\title{
UMA CARACTERIZAÇÃO DO PODER REVOLUCIONÁRIO
}

\author{
A CHARACTERIZATION OF THE REVOLUTIONARY POWER
}

Carlos Frederico Ramos de Jesus ${ }^{1}$

\begin{abstract}
Resumo:
O poder revolucionário, visto nas suas manifestações concretas, deriva da capacidade do ser humano para a ação, que possibilita a criação de algo novo. $O$ novo não necessita da violência para surgir; por isso, o poder revolucionário não traz consigo, necessariamente, a força. A finitude ou-não deste poder é questão que determina se a revolução pode deliberar sempre sobre tudo ou se estas decisões devem ser restritas a um certo ínterim.

Palavras-chave: Poder. Revolução. Fenomenologia. Ação. Violência. Hannah Arendt. Antonio Negri. Liberalismo. Democracia.
\end{abstract}

\begin{abstract}
:
The revolutionary power, seen in its concrete occurrences, derives from men's capacity for action, which enables the creation of something new. The new thing does not need violence to appear, thus revolutionary power does not bring violence necessarily with it. Whether this power ends or not is a question that determines if revolution can always decide about everything or if these general decisions should be restricted to a certain interval.
\end{abstract}

Keywords: Power. Revolution. Phenomenology. Action. Violence. Hannah Arendt. Antonio Negri. Liberalism. Democracy.

\section{Introdução}

Oestudo do poder evidencia imediatamente a dificuldade na sua conceituação. O poder não se presta a definições do tipo "poder é..." porque sempre escapará algo. Se dissermos que poder é violência, alguém poderá responder imediatamente que há várias formas de poder que não envolvem a vis (Kaplan e Lasswell, 1978, p. 111-112) e, mais, que a coação é a própria negação do poder, já que ele pressupõe liberdade de quem obedece: quem ordena não quer se valer da força para ser obedecido (embora possa se valer, como último recurso), pois o seu poder será tanto maior quanto mais livre for a adesão às suas ordens (Ferraz Jr, 2003, p. 38-39).

Max Weber (2004, p. 33) percebeu a vagueza de definições prévias de poder, razão que o levou a escolher o conceito de dominação para o estudo sociológico. Para ele, "[p]oder significa toda probabilidade de impor a própria vontade numa relação

\footnotetext{
1 Mestrando em Filosofia e Teoria Geral do Direito pela Faculdade de Direito da Universidade de São Paulo.
} 
social, mesmo contra resistências, seja qual for o fundamento dessa probabilidade”. No mesmo passo, reconhece que
"[o] conceito de poder é sociologicamente amorfo. Todas as qualidades imagináveis de uma pessoa e todas as espécies de constelações possíveis podem pôr alguém em condições de impor sua vontade, numa situação dada. Por isso, o conceito sociológico de "dominação" deve ser mais preciso e só pode significar a probabilidade de encontrar obediência a uma ordem."

Uma solução para nos aproximarmos da compreensão do poder sem cair em definições reducionistas é não exigir um conceito prévio do que ele é, mas ver como ele se manifesta, como ele aparece. Esta solução é enxergar o poder como fenômeno, ou seja, "objeto específico do conhecimento humano que aparece sob condições particulares, características da estrutura cognoscitiva do homem" (Abbagnano, 2003, p. 437). Isto não implica uma abordagem apenas descritiva. Optar pela análise do poder enquanto fenômeno envolve propor hipóteses para explicar por que ele tem as características que são observadas em suas manifestações. A fenomenologia não dispensa uma compreensão coerente do objeto, ela não se contenta com a mera observação e constatação dos fatos. Ela postula que o estudo do objeto a partir de suas manifestações é uma maneira melhor de o entender do que partir de definições a priori, que podem ser descoladas da realidade e até contrárias a ela.

Como o poder não tem substância, mas é uma relação (Ferraz Jr, 2003, p. 41), vai ser difícil, senão impraticável, percebê-lo em sua pureza, em seu estado bruto. É possível apenas percebê-lo nas situações concretas em que ele sempre se mostra junto com alguma outra coisa. Por exemplo: quando um guarda de trânsito pára um condutor infrator, certamente há aí uma relação de poder, mas que surge de maneira indissociável de outros elementos, como as leis de trânsito, a competência fiscalizatória do policial etc. Daí que a melhor abordagem teórica frente ao poder é a fenomenológica: ela permite que reconheçamos a existência do poder em algumas situações, sem que precisemos defini-lo (o que seria arriscado) ou isolá-lo (o que seria impossível).

Com o poder revolucionário, não é diferente, com a peculiaridade de ele ser um poder que não se manifesta no âmbito de uma ordem jurídica. Embora ele esteja evidentemente situado em um território onde há algum Direito estabelecido, sua finalidade é destruir este ordenamento e fundar um novo. Para o jurista, esta peculiaridade é especialmente desafiadora porque ele está acostumado a perceber as reverberações normativas dos outros tipos de poder, que já têm um enquadramento conceitual na 
ciência jurídica. Por exemplo: a manifestação concreta do poder soberano em um decreto expropriatório é apreendida através do princípio do direito administrativo de supremacia do interesse público sobre o privado. O poder revolucionário não admite este enquadramento, o que torna sua compreensão ainda mais intrincada para o jurista. Por isso, evitar conceituações prévias e partir para a fenomenologia é ainda mais recomendado neste caso.

O método de entender o poder revolucionário como fenômeno parece ter sido o usado pelo texto-base deste trabalho: os capítulos 04 e 05 de On Revolution, de Hannah Arendt (1990). Neles, a Autora, que busca "determinar o caráter essencial do espírito revolucionário" (1990, p. 174), coteja as Revoluções americana e francesa, procurando extrair da história o que caracteriza este "tesouro perdido" do espírito revolucionário. Em vez de teorizar abstratamente, Arendt socorre-se dos acontecimentos para perceber como o poder revolucionário se manifestou naqueles casos e, assim, tentar algumas generalizações a este respeito.

\section{A idéia de revolução}

Antes de entrar no tema principal, necessária uma ressalva sobre a idéia de revolução. Nem toda mudança diametral na organização política de uma comunidade sempre recebeu o nome de revolução. Pelo contrário, a idéia de revolução é historicamente situada: como narra Reinhart Koselleck (1999, p. 225-227; Abbagnano, 2003, p. 859), ela pertence à modernidade. Foi a chamada Idade Moderna que concebeu o fenômeno pelo qual toda a ordem anterior era superada para dar origem a uma nova conformação, assim como os astros mudam periodicamente sua trajetória celeste - o conceito de revolução, aliás, é oriundo da astronomia e a palavra foi emprestada pela filosofia e pela ciência política deste ramo do conhecimento. O norte dos revolucionários era fornecido pela razão, que, após a derrocada da Idade Média e suas justificações políticas de origem teológica, passou a ser o modo de conhecimento mais superior e excelente (Ferraz Jr, 1994, p. 66-73). A razão levava os estudiosos e políticos a concluir que a revolução era não apenas necessária, mas também inevitável (Koselleck, 1999, p. 177), pois a idade da simples crença (fosse na disposição tripartite da sociedade que caracterizava o feudalismo, fosse na sapiência do monarca absolutista) tinha que passar e ceder espaço às luzes do raciocínio, as únicas realmente dignas de crédito.

Esta ressalva é necessária para sabermos que as mudanças políticas radicais que ocorreram antes da modernidade só podem ser chamadas de revoluções se forem 
identificadas com um conceito elaborado posteriormente a elas. Em outras palavras, os romanos, por exemplo, não falavam em revolução, e nós só podemos qualificar a invasão germânica como tal se estivermos cientes de que o conceito é emprestado dos dias de hoje.

Realizada esta breve explicação, pode-se entrar no centro do trabalho: como o poder revolucionário se apresenta, fenomenologicamente? Parece haver três características fulcrais no texto de Arendt: em primeiro lugar, o poder revolucionário é ação; em segundo, não tem como parte necessária a violência; em terceiro, é temporalmente limitado. Explorarei cada uma destas manifestações.

\section{O poder revolucionário enquanto ação}

O caráter inovador e coletivo da revolução deriva do fato de ela ser, acima de tudo, uma ação. Que é ação, para Hannah Arendt? É um dos três modos da chamada vita activa, que pretende designar as relações estabelecidas entre os homens e entre eles e as coisas. Os três modos são a labuta, o trabalho e a ação. A labuta relaciona-se à existência biológica do ser humano, consistindo naquelas atividades necessárias para a manutenção da própria vida. Não só os homens, mas também os demais animais labutam quando realizam atividades indispensáveis à sobrevivência. O trabalho remete à existência artificial do homem, "existência esta não necessariamente contida no eterno ciclo vital da espécie" (Arendt, 2001, p. 15), e pertine às atividades que criam e mantêm os objetos deste mundo artificial. A ação é a única atividade que se realiza diretamente entre os homens, sem a mediação das coisas, na qual eles dialogam, revelam-se a si mesmos e criam o novo (Arendt, 2001, p. 15-17). A labuta é regida pela necessidade; o trabalho, pela utilidade; a ação, pela liberdade.

Os étimos gregos e latinos para a palavra agir revelam características da ação que são relevantes para se compreender seu liame com o poder revolucionário:

$$
\begin{aligned}
& \text { '[O] grego e o latim, ao contrário das línguas modernas, } \\
& \text { possuem duas palavras totalmente diferentes, mas correlatas, } \\
& \text { para designar o verbo 'agir'. Aos dois verbos gregos archein } \\
& \text { ('começar', 'ser o primeiro' e, finalmente, 'governar') e } \\
& \text { prattein ('atravessar', 'realizar' e 'acabar') correspondem os } \\
& \text { dois verbos latinos agere ('pôr em movimento', 'guiar') e } \\
& \text { gerere (cujo significado original é 'conduzir')" (ARENDT, } \\
& \text { 2001, p. 202, ênfase no original). }
\end{aligned}
$$

Toda ação tem duas partes: a primeira, realizada apenas pelo indivíduo ou por um grupo deles, em que ele lança algo novo no mundo (ele é o primeiro, começa, põe 
em movimento); e a segunda, em que as pessoas que circundam o inovador completam sua obra (realizam, acabam, conduzem). A ação precisa de alguém que a comece e necessariamente de uma coletividade que a termine.

O caráter inovador e inesperado da ação é semelhante ao do poder revolucionário. Como aduz Arendt (1990, p. 212-213), a revolução é um princípio que contém em si seu próprio princípio: um início que se dá as próprias normas. No dizer de Antonio Negri (2002, p. 27), “um começo que põe suas próprias condições”. Talvez a maior perplexidade que os juristas enfrentam no estudo da revolução seja a de se deparar com uma ordem que não se guia por regras pré-determinadas, mas constitui suas próprias normas. E isto porque o pensar jurídico (assim como toda a moral) é um pensar segundo regras: quando estas não preexistem ao fenômeno analisado, há uma desorientação para o raciocínio jurídico. Arendt procura solucionar esta perplexidade, mostrando que não apenas a revolução, mas toda a ação humana, é o início de algo antes inexistente e traz consigo o inusitado. E toda a ação é assim "porque cada homem é singular, de sorte que, a cada nascimento, vem ao mundo algo singularmente novo" (Arendt, 2001, p. 191). Fazer sempre algo surpreendente e imprevisível inere à natureza humana e cada pessoa tem inovações diferentes para trazer ao mundo porque cada uma é singular, única. Então, não é de se espantar que o poder revolucionário seja um início que se dê as próprias regras: o Homem também é assim. A constante criação do novo, ínsita à natureza humana, explica a revolução. O germe revolucionário está na condição humana.

Mas ninguém faz uma revolução sozinho, assim como nenhuma ação é desenvolvida sem a coletividade que rodeia o agente. A segunda parte da ação (o prattein, o gerere) indica que ela está sempre situada em um meio, necessariamente composto por outros homens (Arendt, 2001, p. 196-197). “A ação jamais é possível no isolamento”, de maneira que nem mesmo o homem forte pode agir sozinho: se a força é individual, o agir é coletivo (Arendt, 2001, p. 201). Semelhante coisa pode ser dita do poder revolucionário: ele só nasce e vive coletivamente (Arendt, 1990, p. 175). Não é correto dizer que a revolução se faz com a soma dos poderes individuais, pois o poder, assim como a ação, é relacional:

“A gramática da ação: que a ação é a única faculdade humana que demanda pluralidade de homens; e a sintaxe do poder: que o poder é o único atributo humano que se aplica somente ao espaço do mundo intersubjetivo, pelo qual os homens estão mutuamente relacionados" (ARENDT, 1990, p. 175).

O poder revolucionário nasce da relação entre os homens, assim como a ação humana apenas se perfaz, se completa na relação intersubjetiva. 
Arendt louva os revolucionários americanos por terem percebido estas duas características do poder revolucionário e as terem aplicado na prática. Em primeiro lugar, perceberam que o corpo político deveria ser fiel não a algo abstrato (como a nação dos revolucionários franceses), mas a um ato de fundação, porque os princípios que devem guiar a comunidade foram estabelecidos por este ato e não por algo transcendente ou intangível. A fundação da comunidade política é humana e não há nada de errado em guardar respeito a um ato humano pretérito, pois ele encontra em si mesmo o fundamento para firmar regras novas. Em segundo lugar, os revolucionários também perceberam que o poder é algo coletivo, razão pela qual estabeleceram princípios que fomentavam a continuidade do poder: a deliberação coletiva e o cumprimento das promessas mútuas. Eles perceberam o caráter inovador e coletivo do poder revolucionário, à semelhança da ação.

4. O poder revolucionário enquanto não-violência

O poder revolucionário é necessariamente violento? Este tema deve ser abordado porque o senso comum identifica revolução com violência, da mesma maneira que identifica poder com força. Há uma tradição em se enxergarem movimentos revolucionários como vertedores de muito sangue. Arendt, todavia, rejeita esta associação, postulando que a violência, ao menos enquanto vis, não é parte essencial do poder revolucionário. A revolução pode dispensar a violência da mesma maneira que a ação dispensa a força bruta. O novo não necessita da vis para vir ao mundo. Pelo contrário, a "violência nunca gerou algo estável e novo" (Arendt, 1990, p. 209). O fato de o conceito de revolução ser moderno e, portanto, tributário do ideal iluminista, já indica que o poder revolucionário advém muito mais do convencimento e da razão do que da coação; afinal, pelo ideal iluminista, a razão não necessita da força bruta, pois sua força persuasiva já é suficiente, inclusive para garantir resultados muito mais duradouros do que a violência, visto que induz uma adesão voluntária às causas. A força moral deste conceito de revolução torna-o muito distinto do de guerra civil, movimento violento por definição (Koselleck, 1999, p. 226).

É contestável que a Revolução Americana seja exemplo de movimento pacífico, como procura sugerir Arendt. Há quem veja no momento da independência das treze colônias um mero acordo entre os ricos comerciantes da Colônia inglesa, para se libertar do jugo fiscalista da metrópole (Beard, 1941), sendo que a verdadeira revolução que realmente unificou os Estados Unidos como nação - só viria mais tarde, com a Guerra 
de Secessão; e esta foi indubitavelmente sangrenta. Por outro lado, seria incorreto afirmar que a história não dá suporte algum à Autora: a Revolução Gloriosa (1649), a Independência da Índia $(1947)^{2}$ e a Revolução dos Cravos $(1974)^{3}$ resultaram de movimentos pacíficos. O poder revolucionário aparece, muitas vezes, sem a violência, mostrando que ela não é um atributo necessário seu.

A violência que Arendt (1990, p. 208) afirma ser inerente à revolução é diferente da vis, pois ela é ínsita a qualquer ato de criação, que procure extrair o novo do antigo. É a violência na seguinte acepção trazida por Abbagnano (2003, p. 1002): “ação contrária à ordem ou à disposição da natureza." Neste sentido, transformar o barro em vaso implica violar o barro, tirá-lo de sua conformação natural para que ele se torne outra coisa. Esta violência - que também está presente na revolução - não se confunde com a vis, mantendo o poder revolucionário como algo que não implica, em suas manifestações, a força.

\section{O poder revolucionário como algo finito}

Hannah Arendt (1990, p. 205) diz, em certo ponto de On Revolution, que a revolução parece ser o intervalo de tempo entre o "não mais" e o "ainda não". O poder revolucionário aparece como algo por essência limitado no tempo, que começa e tem que necessariamente acabar. Ele destrói a ordem anterior, mas deve necessariamente construir uma nova. A revolução permanente é rejeitada por Arendt (1990, p. 181), pois o poder permanentemente aberto à "força natural da multidão" é contraproducente.

Esta idéia de Arendt parece entrar em conflito com a de ação, que é a base do poder revolucionário. De fato, se a ação é, por definição, a criação do novo, e se esta característica é exclusiva do ser humano, limitar a revolução seria colocar peias na vontade constante de renovação do Homem e impedi-lo de criar. Seria pressupor que não há mais nada de novo que mereça ser criado após a revolução consolidar uma nova ordem institucional. E esta suposição seria contraditória, pois não se pode pensar o novo antes de

\footnotetext{
2 Não se ignoram as lutas religiosas entre hindus e muçulmanos que se sucederam à independência indiana, principalmente devidas à criação de dois Estados independentes: a União Indiana e o Paquistão. Mas o processo revolucionário que levou à independência, baseado na desobediência civil e liderado pelo Mahatma Gandhi, foi pacífico.

3 O relato da cineasta Maria de Medeiros, no filme Capitães de Abril (França, Portugal, Itália, Espanha - 2000), é emblemático do caráter pacífico desta revolução portuguesa. Em uma cena, os tanques do exército avançam por Lisboa rumo à sede do governo. Subitamente, param. O general indaga ao soldado que lidera o comboio por que os tanques pararam. A resposta: "Ó, meu comandante, o sinal está vermelho". O general, não sem parar um instante para pensar sobre o dilema, retruca: "E revolução respeita sinal vermelho? Siga em frente!"
} 
ele ser criado - isso equivaleria a criá-lo (Arendt, 2001, p. 190-191). ${ }^{4}$ Desta forma, seria impossível pensar em todas as novas coisas que poderiam ser idealizadas e concretizadas caso a revolução continuasse para fazer o juízo de valor de que não vale a pena criá-las.

Além de enfrentar estas objeções de matriz lógica, a limitação temporal do poder revolucionário também é atacada do ponto de vista da teoria política. ${ }^{5}$ Antonio Negri, condensando a posição do chamado pensamento crítico quanto à revolução, apresenta fundamentalmente duas inquietações diante da idéia arendtiana.

Em primeiro lugar, a revolução não pode terminar porque só uma "relação aberta entre multidão e potência" realiza plenamente a democracia (Negri, 2002, p. 429). ${ }^{6}$ Se é do povo que todo poder realmente emana, não devem existir barreiras intransponíveis entre a sua vontade e a realização desta. Uma revolução que é concluída e cristaliza uma nova ordem apresenta um obstáculo institucional para futuras mudanças diametrais da comunidade: o povo não pode tudo diretamente, mas só o que a nova constituição lhe permite fazer; quaisquer outras mudanças só podem ser operadas pela via revolucionária. A pergunta que subjaz a esta objeção de Negri é: por que as pessoas que realizaram a revolução devem ter mais poder do que as que vêm depois, inclusive diminuindo suas possibilidades de agir? Por que o povo anterior deve ter mais poder do que o povo posterior? A limitação no tempo do poder revolucionário seria antidemocrática.

Em segundo lugar, a efetividade dos direitos e das funções institucionais estabelecidas em uma Lei Maior depende de o povo efetivamente os querer (Negri, 2002, p. 37). Se não quiser, a Constituição não bastará para realizá-los: continuarão sendo não mais do que regras escritas na "folha de papel" de que falou Lassalle (2004, p. 56-57, 6770), sem nenhum impacto prático. Ora, uma revolução que termina poderá eventualmente acarretar, no instante seguinte ao seu término, uma insatisfação popular com o que está firmado lá. Ainda que isto não leve a uma nova revolução, levará a uma eficácia (no sentido de eficácia social, efetividade (Ferraz Jr, 1994, p. 198-199)) reduzida destas normas - que correspondiam à vontade dos revolucionários, mas não correspondem à vontade do povo naquele momento. Por isso que, para Negri (2002, p. 40), “[o] único conceito possível de

\footnotetext{
4 Karl Popper também apresenta este argumento para demonstrar a impossibilidade de as inovações radicais serem previstas anteriormente à sua realização: pensar a roda antes de ela existir seria criá-la (apud MACINTYRE, 2003, p. 93).

5 O conceito de teoria política adotado é o de Isiah Berlin (2002, p. 228): "A teoria política é um ramo da filosofia moral que parte da descoberta, ou aplicação, de noções morais na esfera das relações políticas".

V. também Koselleck (1999, p. 140-141), identificando Rousseau como um defensor da revolução permanente.
} 
constituição é o de revolução: poder constituinte concebido como procedimento absoluto e ilimitado."

Negri postula, portanto, que a limitação temporal do fenômeno revolucionário é antidemocrática e ineficaz. A permanência do poder revolucionário é a única forma de garantir que as rédeas do Estado estejam efetivamente nas mãos do povo e que o Direito tenha efetividade.

Hannah Arendt parece não se abalar com estes posicionamentos porque sua idéia de liberdade é diferente. A liberdade não pode florescer onde as condições políticas são constantemente sujeitas à mudança. Ela requer, ao contrário, estabilidade, segurança, certeza de que algumas coisas continuarão como estão (Arendt, 1979, v. 3, p. 231):

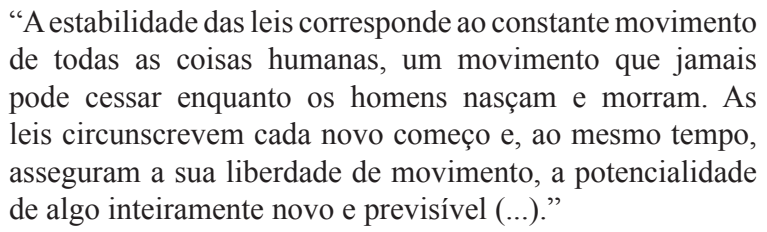

Embora o Homem seja um dinamismo (porque está sempre criando), ele precisa que algumas coisas sejam estáticas: para ele, por exemplo, lançar novas e contestadoras idéias, ele precisa ter a segurança de que o direito à liberdade de expressão do pensamento não sumirá do dia para a noite. A necessidade de que a revolução acabe explica-se, em Arendt, pelo seu temor de que a força da multidão tolha as condições que possibilitam a ação humana.

Em reforço a seu argumento, pode-se trazer uma contribuição de Carlos Santiago Nino. Partilhando do mesmo temor que Arendt, Nino (1989, p. 103) busca explicar por que o princípio da autonomia da pessoa humana se impõe, acima de qualquer legislação positiva. E a razão é que um procedimento deliberativo (que ele chama de discurso moral) que parte da autonomia dos agentes não pode, ao final, negar esta mesma autonomia (Nino, 1989, p. 230-234). Se o fizesse, estaria negando a si próprio. A autonomia da pessoa humana é condição de validade do discurso moral. Quem nele ingressa (numa democracia, toda a sociedade ingressa) deve ter isto como pressuposto. Então, se uma ameaça à liberdade é identificada, deve-se montar um esquema teórico que a afaste: no caso de Arendt, se o poder revolucionário permanente ameaça a liberdade, então sua duração deve ser restringida.

$\mathrm{O}$ dissenso entre Hannah Arendt e Antonio Negri quanto à duração do poder revolucionário expõe, na verdade, uma clivagem mais profunda: entre (à míngua de termos melhores) liberais e democratas, entendidos nas açepções seguintes. Os liberais 
defendem que o Direito deve-se curvar a preceitos derivados da razão e, por isso, "autoevidentes" (como disseram os revolucionários americanos); a conseqüência disto é que as deliberações populares que violarem estes preceitos são írritas. Já os democratas propugnam simplesmente que tudo que o povo decidir deve ser cumprido, não importando quais interesses sejam prejudicados. Por isso, Paulo Bonavides (2001, p. 50-55) afirma que "democracia liberal" é uma expressão paradoxal, já que democracia e liberalismo seriam diametralmente opostos.

Na verdade, os liberais (como Arendt) têm um conceito de democracia: uma forma de governo em que o povo pode deliberar sobre tudo, exceto sobre aquele núcleo imutável de direitos que são produto da razão. Estes direitos são estabelecidos desta forma "pétrea" exatamente para impedir que o povo, iludido, possa abrir mão de suas prerrogativas naturais. Os democratas, todavia, dirão que esta idéia é paternalista, porque pressupõe a incapacidade de o povo sempre decidir sobre seus destinos e estabelece a necessidade de ele ser tutelado. Dirão também que é elitista, porque pressupõe que algumas pessoas podem dizer o que é certo e o que é errado, à revelia da vontade popular, simplesmente devido à sua ilustração, ao seu conhecimento.

Vê-se que o debate quanto à extensão temporal do poder revolucionário expõe controvérsia teórica mais acirrada, que está longe de chegar a um termo. Se assistimos a este embate preocupados em aprofundar a democracia, devemos admitir que as ponderações de Negri não podem ser desconsideradas, pois a idéia de que o povo não deve decidir tudo, porque pode se enganar, tem uma matriz elitista inegável: basta lembrar que era este o argumento principal contra o sufrágio universal (Bonavides, 2001, p. 188192). E também não se pode desprezar a preocupação de Arendt com a estabilidade de certos direitos, pois é difícil para o ser humano viver na incerteza.

\section{Conclusão}

As idéias de Hannah Arendt permitem que nos aproximemos do poder revolucionário sem a pretensão de defini-lo, mas de apreender a forma como ele aparece. Ao final, chegamos a constatações interessantes: que seu caráter inovador e coletivo deriva da própria natureza humana, pois ele é uma ação; que ele não implica violência; e, finalmente, que sua duração (limitada ou ilimitada) aponta para uma tensão entre democracia e liberalismo, difícil de ser resolvida. Esta última constatação tem profundas implicações institucionais: uma revolução ilimitada implicaria um Estado em que o povo pode modificar qualquer coisa a qualquer tempo, ao passo que uma revolução limitada 
deságua em uma ordem jurídica na qual algumas regras só podem ser modificadas por uma nova revolução.

Todavia, talvez seja melhor não atribuir ao poder revolucionário limites que ele parece não ter. Ninguém menos do que Kelsen (1999, p. 396) (também ele, como Arendt, um judeu que sofreu a perseguição nazista) disse, ao final da sua Teoria Pura, que a chamada "interpretação correta" das normas "é uma ficção de que se serve a jurisprudência tradicional para consolidar o ideal da segurança jurídica. Em vista da plurissignificação da maioria das normas jurídicas, este ideal somente é realizável aproximativamente". Se nem com normas estabelecidas pode haver certeza e segurança jurídicas, que dirá numa revolução? Talvez o inesperado, que sempre causa medo, seja o preço que se pague pela condição humana, de eterna possibilidade de criação do novo, para o bem ou para o mal.

São Paulo, junho de 2007.

\section{Referências}

ABBAGnAnO, Nicola. Dicionário de filosofia. Tradução de Alfredo Bosi. 4. ed. São Paulo: Martins Fontes, 2003.

ARENDT, Hannah. A condição humana. Tradução de Roberto Raposo. 10. ed. Rio de Janeiro: Forense Universitária, 2001.

. As origens do Totalitarismo: Totalitarismo, o Paroxismo do Poder. Tradução de Roberto Raposo. Rio de Janeiro: Documentário, 1979. v. 3.

. On Revolution. London: Penguin, 1990.

BEARD, Charles. An economic interpretation of the Constitution of the United States. 2. ed. New York: MacMillan, 1941.

BERLIN, Isiah. Dois conceitos de liberdade. In: HARDY, Henry; HAUSHEER, Roger (Orgs.). Ensaios sobre a Humanidade. São Paulo: Companhia das Letras, 2002.

BONAVIDES, Paulo. Do Estado liberal ao Estado social. 7. ed. São Paulo: Malheiros, 2001.

FERRAZ JÚNIOR, Tercio Sampaio. Estudos de filosofia do direito. 2. ed. São Paulo: Atlas, 2003. . Introdução ao Estudo do Direito. 2. ed. São Paulo: Atlas, 1994.

KAPLAN, Abraham; LASSWELL, Harold. Poder e sociedade. Brasília: UnB, 1978. 
KELSEN, Hans. Teoria pura do direito. Tradução de João Baptista Machado. 6. ed. São Paulo: Martins Fontes, 1999.

KOSELLECK, Reinhart. Crítica e crise: uma contribuição à Patogênese do mundo Burguês. Tradução de Luciana Villas Boas Castelo-Branco. Rio de Janeiro: UERJ/Contraponto, 1999.

LASSALLE, Ferdinand. O que é uma Constituição? Tradução de Hiltomar Martins Oliveira. Belo Horizonte: Líder, 2004.

MACINTYRE, Alasdair. After virtue. 2. ed. Notre Dame: University of Notre Dame, 2003.

NEGRI, Antonio. O poder constituinte. Tradução de Adriano Pilatti. Rio de Janeiro: DP\&A, 2002.

NINO, Carlos Santiago. Ética y derechos humanos: un ensayo de fundamentación. 2. ed. Buenos Aires: Astrea, 1989.

WEBER, Max. Economia e sociedade. Tradução de Regis Barbosa e Karen Elsabe Barbosa. São Paulo: UnB/Imprensa Oficial, 2004. v. 1. 